\title{
A survey of anthelmintic resistance in Angus bulls participating in centralized performance tests in Appalachia
}

\author{
Roger Tyler Rohrbaugh \\ rtrohrbaugh@mail.wvu.edu
}

Follow this and additional works at: https://researchrepository.wvu.edu/etd

Part of the Beef Science Commons, and the Parasitology Commons

\section{Recommended Citation}

Rohrbaugh, Roger Tyler, "A survey of anthelmintic resistance in Angus bulls participating in centralized performance tests in Appalachia" (2021). Graduate Theses, Dissertations, and Problem Reports. 8257. https://researchrepository.wvu.edu/etd/8257

This Thesis is protected by copyright and/or related rights. It has been brought to you by the The Research Repository @ WVU with permission from the rights-holder(s). You are free to use this Thesis in any way that is permitted by the copyright and related rights legislation that applies to your use. For other uses you must obtain permission from the rights-holder(s) directly, unless additional rights are indicated by a Creative Commons license in the record and/ or on the work itself. This Thesis has been accepted for inclusion in WVU Graduate Theses, Dissertations, and Problem Reports collection by an authorized administrator of The Research Repository @ WVU. For more information, please contact researchrepository@mail.wvu.edu. 
A survey of anthelmintic resistance in Angus bulls participating in centralized performance tests in Appalachia

Roger T. Rohrbaugh

Follow this and additional works at: https://researchrepository.wvu.edu/etd

Part of the Animal Studies Commons, and the Beef Science Commons 
A survey of anthelmintic resistance in Angus bulls participating in centralized performance tests in Appalachia

\author{
Roger Tyler Rohrbaugh
}

Thesis submitted to the Davis College of Agriculture, Natural Resources and Design at West Virginia University in partial fulfillment to the requirement for the degree of

Master of Sciences in Animal Physiology

Scott A. Bowdridge, Ph.D.

Scott P. Greiner, Ph.D.

Kevin S. Shaffer, Ph.D.

Division of Animal and Nutritional Sciences

Morgantown, West Virginia

2021

Keywords: Angus, anthelmintic resistance, performance, cattle, Appalachia region

Copyright 2021 Roger T. Rohrbaugh 


\section{Abstract \\ A survey of anthelmintic resistance in Angus bulls participating in centralized \\ performance tests in Appalachia}

Roger T. Rohrbaugh

Resistance to anthelmintics, more commonly referred to as "de-wormers," has been on the rise in parasites that affect cattle. Parasite infection can have severe impacts on calf productivity resulting in reduced profitability. Therefore, we sought to better understand anthelmintic resistance in Appalachia by surveying Angus bulls entering performance tests in VA and WV. During a four-year period, over 1050 Angus bulls were tested at bull development facilities in Wardensville, WV, Culpeper, VA and Wytheville, VA. Fecal samples were collected at arrival and 14-21 days later for determination of fecal egg count (FEC) reduction. Upon arrival, all bulls received either fenbendazole (Wardensville, WV) or moxidectin (both VA tests). In Wardensville, treatment with albendazole had a 96.5\% FEC reduction, whereas, treatment with moxidectin at Culpeper and Wytheville stations resulted in FEC reduction of $26.3 \%$ and 28.6\%, respectively. Gain during these 14 days were lower for bulls from Wytheville $(0.89 \mathrm{~kg} / \mathrm{d})$ than those of Culpeper and Wardensville (1.93 and $2.11 \mathrm{~kg} / \mathrm{d}$; respectively). These data can be associated with higher bull FEC after treatment in Wytheville (98.8 eggs/g) compared to bulls in Wardensville and Culpeper (3.3 and $47.8 \mathrm{eggs} / \mathrm{g}$ respectively). Additionally, there was a negative correlation between delivery FEC and average daily gain. Taken together these data demonstrate resistance to moxidectin in bulls from the Appalachian region indicating cattle exhibiting these same results will have reduced performance in grazing operations to feedlots and/or for stockers/backgrounders. 


\section{Acknowledgements}

The completion of this degree would not have been possible without the help of several people. First off, I would like to thank Dr. Scott Bowdridge for all the guidance and leadership he showed me and the numerous of things that he has taught me during my time as his student. The things I was taught I will use and cherish for many years to come as it has made me a better made me a better instructor and science minded. Next, I would like to thank Drs, Scott Greiner and Kevin Shaffer for coordinating with me and allowing me to collect my samples to make this research possible.

An extensive thank you goes out to the Bowdridge lab and all involved from collecting my samples to processing them. During my research alone we processed nearly 3000 fecal samples and without you guys none of that would have been possible. Also, the farm staffs from Wardensville, WV, Wythville, VA, and Culpeper, VA bull test, thanks for allowing me to conduct my research and allow me to use these bulls for sampling. With your willingness to help it has made my sample collections much easier.

Lastly, I would like to thank the authors family for the support given during this time. The motivation and support given will always was appreciated and made this process more enjoyable. I would like to give a special thanks to my girlfriend Jae, without your help and support I would have struggled way more during this time. Thank you for continuing to push me to do better every day. 


\section{Contents}

A survey of anthelmintic resistance in Angus bulls participating in centralized performance tests in Appalachia

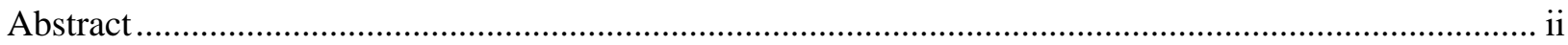

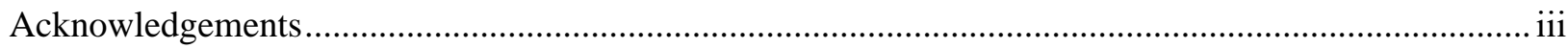

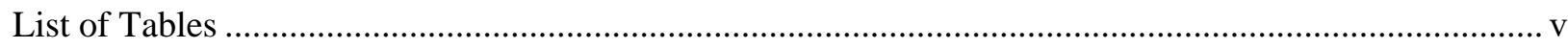

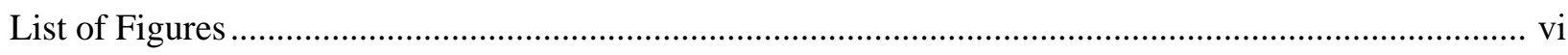

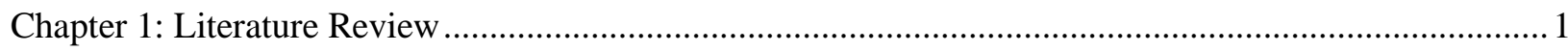

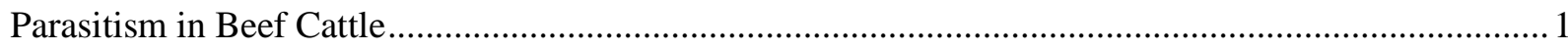

Effects of Parasitism the in Cow-calf production system ............................................................... 3

Effects of Parasitism in Stocker Cattle and developing heifers ...................................................... 4

Helminth parasites common to Beef Cattle ....................................................................................... 5

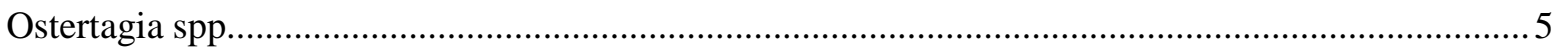

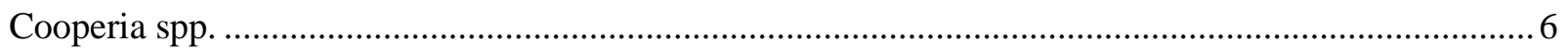

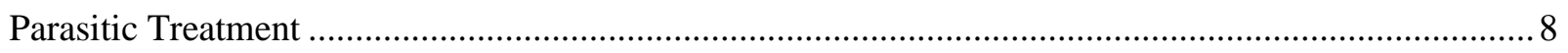

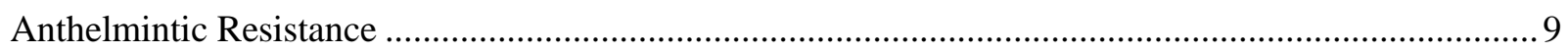

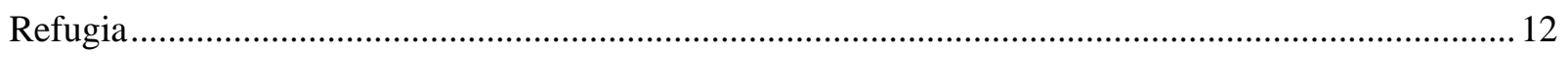

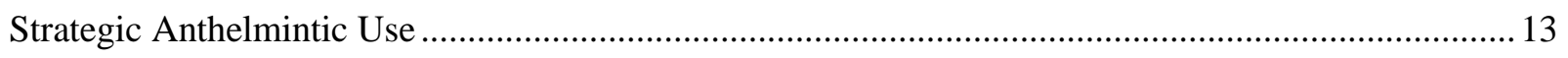

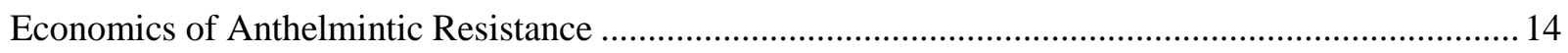

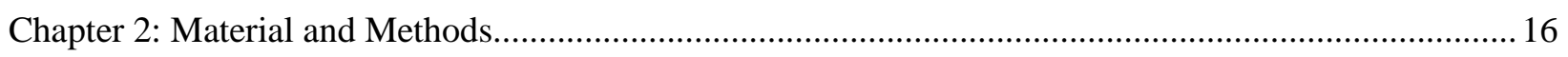

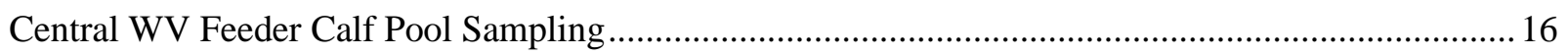

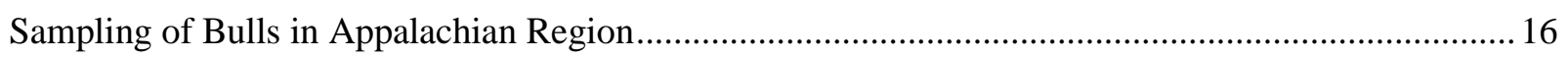

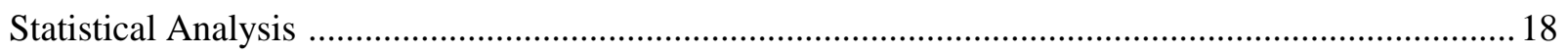

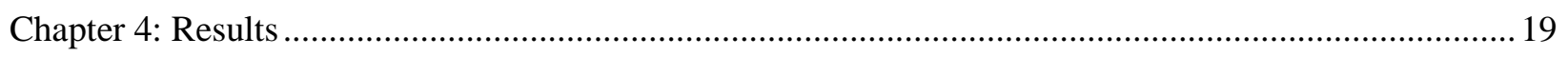

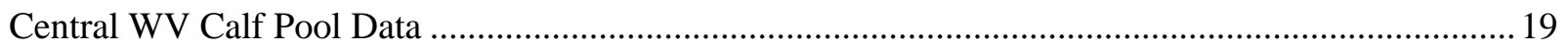

Anthelmintic Resistance at Appalachian Bull Test Stations ........................................................... 19

Transition Average Daily Gain at Appalachian Bull Tests Stations ................................................. 19

Arrival fecal egg count at Appalachian Bull Tests Stations .............................................................2 20

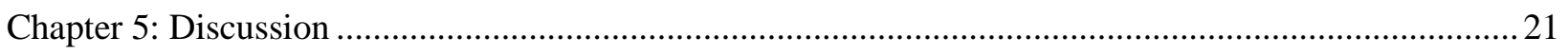

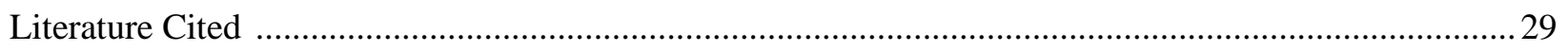




\section{List of Tables}

Table 1: Anthelmintic resistance in central WV Calf Pool.

Table 2: Anthelmintic resistance measured in fecal egg count reduction percentage (FECR\%)

Table 3: Performance and FEC data from bull tests in Appalachian region 


\section{List of Figures}

Figure 1 Comparison of Growth performance to on-test FEC 


\section{Chapter 1: Literature Review}

\section{Introduction}

Cattle producers in the Eastern and Southeast U.S. primarily base their revenue off of the cow-calf sector. The Appalachian region of the US is known for its grasslands but also rugged and un-even terrain. This rugged terrain is managed to produce grass as a forage source for ruminant production. Forage production in this region effectively supports cow/calf production. Grazing cattle is not without its disadvantages as parasites become a concern, as they can impact cattle performance and overall health. Moreover, parasitized calves leaving Appalachia for midwest feedlots have documented increase in transition time affecting profitability especially for producers opting for retained ownership. To assure the utmost quality, precautions must be taken to maintain a healthy herd and reduce detrimental effects of parasitism.

\section{Parasitism in Beef Cattle}

Parasites can be detrimental to growth, productivity, reproduction, and impair health in cattle. Reduction of any of these factors can have severe economic impact, especially considering cattle production is the largest single agricultural sector in the U.S. with cash receipts of \$66.2 billion in 2019 (Lawrence and Ibarburu, 2007). Efficiency is critical, as producers try to maintain consumer demands of wholesome and affordable food. Couple these market drivers with an increase incidence of anthelmintic resistance, demand better strategies to limit the impact of parasitism on beef production whole prolonging the effectiveness of anthelmintics.

Two classes of parasites most known to affect beef cattle are internal parasites and external arthropods. For the purpose of this research focus will be placed on internal helminths parasitism. Better known as gastrointestinal nematodes or GIN, the most common GIN found in 
cattle are Ostertagia spp and Cooperia spp. The distribution, occurrence, and intensity of parasites varies enormously between hosts from different sites, seasons, and years, in part due to interspecific sensitivity of infective stages to variable environmental conditions (Beck et al., 2015). Parasites typically thrive in temperate conditions that have adequate rain fall.

Treatment of GIN infection normally involves use of anthemintic (de-wormers). These products use different mechanisms that to inhibit worm mobility of feed or paralyzing them. However, over-use of anthelmintics has caused them to fail as worms developed resistance. Every time an anthemintic is used, worms can develop resistance and further reduce efficacy of that anthelmintic. Thus, it is important to find a cost-effective parasite control program that is strategic yet flexible to tailor scheduling for your region and cattle operation differences (Corwin, 1997). Applying caution about which cattle to deworm, when to deworm and which anthelmintic is advised. Determining economic impacts of parasitism is complicated, as performance parameters must be used to measure differences between treated and untreated animals or herds. Furthermore, fecal egg count is not evaluated commonly in cattle, especially in relationship to traits such as gain, reproduction, and lactation. To address this concern fecal egg count reduction test (FECRT) is the only true measure of anthelmintic efficacy. This includes taking a fecal sample prior to and after an anthelmintic administration to determine egg reduction from that animal. One study measured FECR\% amongst several types of anthelmintic. A control group left untreated carried a -95\% meaning from their worm count nearly doubled in this time, the other cattle that were treated saw reduction percentages of Levasole (99\%), Cydectin (77\%), Panacur (68\%), Eprinex (-7\%), Dectomax (-35\%) and IvomecPlus (-78\%). (Gasbarre et al., 2009). These data indicate that many of the anthelmintics formulated for pour-on administration have significant resistance to them within the cattle GIN population. 


\section{Effects of Parasitism the in Cow-calf production system}

Young calves are most susceptible to effects of parasitism. One study conducted over three years showed that ADG of untreated heifer calves was $0.79 \mathrm{~kg} / \mathrm{d}$, while heifer calves treated with the ivermectin SR bolus in mid-summer was $0.88 \mathrm{~kg} / \mathrm{d}$; the difference of $90 \mathrm{~g} / \mathrm{d}$ was significantly different $(P=0.0118)$. A SR bolus is a bolus that releases little amounts of ivermectin for an extended period of time to maximize the length of anthelmintic activity. The average rate of daily liveweight gain in untreated bull calves was $0.91 \mathrm{~kg} / \mathrm{d}$, while the bull calves treated with the ivermectin SR bolus in mid-summer was $1.01 \mathrm{~kg} / \mathrm{d}(\mathrm{P}=0.0169)$ (Forbes et al., 2002). Thus, the largest effect of parasitism in pre-weaned calves is loss of growth which can result in lower weaning weights. Weight loss in calves infected by Osteragia spp. can be linked to suppressed appetite all the way to profuse diarrhea. Therefore effects of parasitism manifest in symptoms such as: rapid weight loss, submandibular edema, increased mortality, anemia, and generally poor condition with a rough hair coat (Myers and Taylor, 1989).

According to an economic analysis report about beef cattle technology, de-wormers are the technology that affects weaning weight the most (Lawrence and Ibarburu, 2007). The larger the effect of a technology on production efficiency, the larger its effect on the cost of production. The expected impact on breakeven selling price of de-wormer elimination was $34.3 \%$ which represents an added cost of $\$ 165.47 /$ head produced (Lawrence and Ibarburu, 2007). As is easy to see the gains from treated calves during the summer months, effective parasite management in calves prior to weaning can impact weaning weight and also future weight gain. In general cows have developed immunity to parasites as they have years of exposure to these parasites and with adequate nutrition they don't usually show and signs of parasitism or have any negative effects. 


\section{Effects of Parasitism in Stocker Cattle and developing heifers}

Stocker calves are the calves that set in between weaning and the feedlot stage. These calves typically weight 400-900 lbs. and are raised either on full feed or out on pasture. If they are chosen to be developed on pasture, parasite management is crucial for proper growth and maintenance of those cattle. Thankfully enough, technology exists to help achieve those goals. When looking at technology, de-wormers can have some of the greatest affects towards cattle. The higher the effect of a technology on production efficiency, the larger its impact on cost of production. The estimated effect on the breakeven price of eliminating de-wormers in stocker cattle was $2.7 \%$ which represents a cost of $\$ 20.77 /$ head produced (Lawrence and Ibarburu, 2007).

The development of heifers is very important for all producers. Seeing that heifers are the new generation of genetics, proper care and treatments should be used to ensure efficient development. Heifers treated for GIN, had higher means weights and higher body condition scores than heifers left untreated (Loyacano et al., 2002). Not only did the treatment affect their performance, but their offspring's performance was greater as well. Calves from untreated dams had lighter birth weight calves born when compared to treated dams. After adjusting the weaning weight for age and sex, the calves from treated dams were significantly heavier at weaning time than dams not treated for GIN (Loyacano et al., 2002). Another study involving heifer development showed heifers treated with Ivermectin gained $181 \%$ more weight than heifers receiving no treatment (Sanson et al., 2003). These data continue to show a role for anthelmintics in reducing negative impact at parasitism on growth. 


\section{Helminth parasites common to Beef Cattle}

Ostertagia spp.

Ostertagia spp. can be found in the abomasum tissues, also considered the true stomach

of cattle. Cattle become affected through oral administration of this parasite by infected pastures, and once infected the parasite begins its life cycle. The life cycle of Ostertagia starts in the abomasum where adult females lay eggs that travel through the intestine and are excreted in feces. They then hatch in the dung pat into first-stage larvae or L1. As they molt for the first time, they are called second stage larvae or L2 and at this point they feed off the bacteria or other nutrients that make up the feces. Next they molt into third stage larvae. In the third stage the larvae cannot feed due to a retained cuticle from the second stage for protection. Third stage larvae can survive for up to a year on pasture and travel short distances within the feces. (Smith, 1972). The third stage is also considered their infective stage as they await to be consumed from the vegetation they are attached too. The developmental period from L1 to L3 stage can occur in as little as two-three weeks. Once ingested, they lose their protective sheath and barrow into the gastric gland of the fundic and cardic regions of the abomasum and then become forth-stage larvae (L4). Some of ingested L3 larvae can enter a phase called hypobiosis and can survive in this stage for several months. Temperature or weather conditions are the main components to why this happens. If the conditions are not suitable for eggs to be hatched outside, the larvae will enter this stage to ensure when they do become adult their eggs have a greater chance of survivability. As they start to feed the lining of the abomasum will start to be damaged and the longer the L4s go untreated the greater the damage will occur. Such losses have been associated with marked changes in feed intake, gastrointestinal function, protein, energy and mineral metabolism, and in body composition. (Fox, 1997) 
To better understand the effects of Ostertagia on the host, it is criticial to specifically describe the host: parasite interface. As Ostertagia enters the gastric gland, it interrupts with animal's ability to properly digest feedstuffs efficiently. Reduction in acid output results from the replacement of functional parietal cells with those of reduced activity rather than a direct response to parasite secretions (Murray et al., 1970; McKellar et al., 1990). The parietal cells are important for digestive purposes, as they produce hydrochloric acid (HCL) necessary for protein digestion. Without proper working parietal cells, there is a lack of HCL and thus lower efficiency for that animal to digest feed. The decrease of acid productions also leads to increased $\mathrm{pH}$. With a higher $\mathrm{pH}$. you get an absence of proteolytic pepsin because, in the absence of low abomasal $\mathrm{pH}$, pepsinogen is not activated. Digestion eventually ceases at $\mathrm{pH}$ 5, and bacterial overgrowth may occur; this contributes to diarrhea as a consequence. (Myers and Taylor, 1989). Studies have shown that Ostertagia can increase the levels of blood gastrin in animals which is associated with reduced appetite (Fox, 1997). By reducing appetite, infected animals will consume less feed daily and exhibit reduced performance.

Recent research has shown that over one third of adult cattle at slaughter have extensive gross, pathological changes in the abomasal mucosa, typical of ostertagiosis (Larraillet et al., 2012). This indicates that commonly used anthelmintics are not effectively removing parasites. Since use of these anthemintics has not changed, it is logical to assume that a continued frequency of resistance genetics has been propagated in worm populations.

\section{Cooperia spp.}

Another common species seen in grazing cattle is Cooperia. Unlike Ostertagia, Cooperia resides in the small intestine of young calves. "Cooperia spp. have become the most prevalent 
parasite in United States cow/calf operations as observed in the USDA NAHMS Beef Cow/Calf survey in 2008" (Stromberg et al., 2012). Cooperia typically reside in the first part of the small intestine, called the duodenum. Although Cooperia are not blood feeders, this doesn't mean they are not problematic for cattle. As expected, the normal clinical signs as observed in parasitic infections include poor weight gain, diarrhea, weight loss, and loss of appetite. This comes from the worm's ability to stunt the intestinal villi thereby reducing the animal's ability to absorb nutrients. These effects on performance have been demonstrated in studies where control cattle (uninfected) gained weight $7.4 \%$ more rapidly than infected animals, $(1.47 \mathrm{~kg}$ vs. $1.36 \mathrm{~kg}$; respectively) $(P=0.02)$. Additionally infected animals also consumed $0.68 \mathrm{~kg}$ less dry feed than control cattle $(P=0.02)$ (Stromberg et al., 2012). These data illustrate the potential economic impact Cooperia infection can have in growing cattle over time.

The lifecycle for Cooperia is similar to other trichostrongolid parasite nematodes, they must get ingested in order to infect the animal. As the animal ingests L3 larvae, larvae will travel through the digestive tract until they reach their tissue niche. In the small intestine, Cooperia larvae will molt into an adult and females will start to lay eggs that will be passed along with the fecal matter. The eggs will be defected out with the dung pat where those eggs will hatch and molt into L1 larvae. Once they have molted into the L2 stage they will feed on nutrients from the dung pat and continue to develop and in 1 week they will molt into a L3. Once they are L3's they can be consumed out on the pasture and travel to the small intestine and molt into adult worms and start the cycle over again. Cooperia typically have a prepatent period of 2 to 3 weeks. A prepatent period is the time it takes from infection until that first egg is shed. With such short prepatent periods, these worms can adapt to certain drugs and anthelmintic is a short period and start to develop resistance. 


\section{Parasitic Treatment}

In the U.S. there are 3 classes of anthelmintic approved for use in beef cattle:

Benzimidazoles, Macrocyclic lactones, and Imidazole's. Benzimidazoles are considered white de-wormers and are usually administered as an oral drench. Macrocyclic lactones are typically administered as an injectable or topical (pour-on). Lastly, Imidazole's which are the least used amongst large ruminants, are normally delivered orally as a liquid or a bolus. Although there is no lack of worms, the ability for pharmaceutical companies to develop new drugs is very difficult. The cost of development of a new drug is estimated at US \$400 million for livestock use (Abongwa et al., 2017). The paragraphs below detail each drug class common names, mode of action, effectiveness on parasites life stage and meat and milk withdrawal.

Imidazothiazoles are the oldest of the anthemintic classes. They act as nicotinic acetylcholine receptor (nAChR) agonists. They bind to nAChRs on body wall muscles, causing spastic paralysis of the worm, and hence, its expulsion from the host (Abongwa et al., 2017). Examples we see of these are levamisole and tetramisole. Levamisole is the mainly used in small ruminants where resistance is already built from the other two drug classes.

Common examples of benzimidazoles are Valbazen®, Safeguard®, and Synanthic $₫$. Benzimidazoles are considered a broad-spectrum drug that kills most major adult GIN parasite such as adult Ostertagia ostertagi, adult and fourth stage larvae Haemonchus contortus \& H. placei, adult and fourth stage larvae Trichostrongylus axei; adult and fourth stage larvae Bunostomum phlebotomum, Nematodirus helvetianus, Cooperia punctata \& C. oncophora, Trichostrongylus colubriformis, and Oesophagostomum radiatum. These drugs work by selectively binding with high affinity to parasite $\beta$-tubulin and inhibit microtubule 
polymerization. This results in the destruction of cell structure and consequent death of the parasite. (Abongwa et al., 2017)

Common examples of macrocyclic lactones (ML) are Cydectin®, Dectomax ${ }^{\circledR}$, and Ivomec ${ }^{\circledR}$. They work to kill the following GIN: Ostertagia ostertagi adults and L4, O. lyrata adults, Haemonchus placei adults and L4, Trichostrongylus axei adults and L4, T. colubriformis adults and L4, Cooperia oncophora adults and L4, C. pectinata adults, C. punctata adults and L4, C. surnabada adults, Bunostomum phlebotomum adults, Oesophagostomum radiatum adults and L4, and Trichuris spp. Macrocytic lactones also carry external parasite control as well, controlling lice, grubs, mites, and flies. Macrocyclic lactones bind to glutamate-gated chloride ion channels in invertebrate nerve and muscle cells. The cell membranes then develop an increased permeability to chloride ions causing hyperpolarization of affected cells and subsequent paralysis and death of the parasite. Medications in this class also interact with other ligand-gated chloride channels, including ones gated by gamma aminobutyric acid (GABA) (MACROCYCLIC LACTONES Veterinary—Systemic, 2006). Unlike the benzimidazoles, macrocyclic lactones have a duration of persistent activity against parasites that can last 14-45 days. In the case for Long Range extended release, that activity can last anywhere from 100-150 days (LongRange ${ }^{\circledR}$ (eprinomectin) | Boehringer Ingelheim Vetmedica)

\section{Anthelmintic Resistance}

Since the first reports of resistance to the broad spectrum anthelmintics were made some three decades ago, this phenomenon has changed from being considered merely as a parasitological curiosity to a state of industry crisis in certain livestock sectors (Waller, 1997). Anthelmintic resistance involving the gastrointestinal nematodes of small ruminants is escalating globally, to the extent that in certain countries, such as South Africa, it has already reached 
alarming proportions, and is affecting practically all the anthelmintics (Wyk and Aucamp, 2001). A search of the literature returned 145 documented cases of AR in nematode parasites in cattle, involving all three of the broad-spectrum anthelmintic classes and at least ten species of nematodes; of these, a large majority have been reported in the past five years (Sutherland and Leathwick, 2011). This should be concerning to the cattle industry as it is headed the same direction, however, it hasn't gained as much attention because large ruminants are not considered as severely affected. Consequently, the problem of anthelmintic resistance in parasite affecting beef cattle are starting to occur more often. Previous studies on a beef cattle backgrounding operation in the U.S. upper midwest had demonstrated the existence of cattle nematode parasites resistant to ivermectin, milbemycin, and benzimidazole (Gasbarre et al., 2009a). Since then, research into the pathophysiology of infection has focused on three main areas: mechanisms of appetite depression; changes in gastrointestinal function; and alterations in protein metabolism (Fox, 1997).

One study, conducted in North America for anthelmintic resistance was done in 2003 looking at steers and heifers purchased form the southeast. These calves were purchased during the winter of 2003 and treated with Dectomax injectable and sent to Mississippi and Alabama to be backgrounded for 30-60 days and afterwards the animals were shipped to Wisconsin. Data from this study, reported fecal egg counts reduction percentages as followed; Untreated-46\%, Ivermectin injectable-52\%, Moxidectin pour-on-72\%, Doramectin injectable-61\%, Eprinomectrin pour-on-8\%, and Albendazole oral-68\%. To put this in context the World Association for Advancement of Veterinary Parasitology (WAAVP) guidelines, anything below 95\% as resistance. Applying this standard to the previous study reveals all drugs in this 
population have significant parasitic resistance. This was the first report of anthelmintic resistance in America cattle parasites (Gasbarre et al., 2009b).

Currently, parasites of the genera Cooperia and/or Haemonchus resistant to generic or brand-name macrocyclic lactones have be demonstrated in more than half of all operations examined (Gasbarre, 2014). This could be contributed due to the ease and indirect benefits from certain macrocyclic lactones. When evaluating what contributed to the rise of resistance it is easy to see that the combined endo- and ectoparasite activity, convenient pour-on formulation and low cost of macrocyclic lactone drugs such as ivermectin have resulted in their widespread use for parasite control in cattle for decades. (Avramenko et al., 2020). Efficacy and ease of application/administration were the attributes most frequently cited as being important or very important in choosing a deworming product (NAHMS, 2009). As selecting anthelmintic for ease of application was a high priority, that led to overuse and consequently an increase in parasitic resistance. For operations that had un-weaned calves or weaned stocker calves, more than $50 \%$ usually dewormed these animals one or more times per year (53.7 and 54.1 percent, respectively). Approximately, 7 of 10 operations (69.5 percent) dewormed replacement heifers 1 or more times per year, and over 8 of 10 operations ( 81.7 percent) dewormed cows 1 or more times per year (USDA, 2009)

With the overuse of macrocyclic lactones in North American cattle, resistance is now common in gastrointestinal nematodes. Although benzimidazoles are highly effective against a large range of internal nematode parasites, their lack of ectoparasite activity and less convenient oral formulation has meant they have been used less often in cattle, particularly in North America (Avramenko et al., 2020). Consistent with the relatively limited use, there has, as yet, only been a few cases of confirmed benzimidazole-resistant parasites in North American cattle 
(Gasbarre et al., 2009). However, in countries where the benzimidazoles have been more heavily used in cattle, such as New Zealand, Australia and South America, resistance is becoming widespread in gastrointestinal nematodes of cattle (McKenna, 1991); (Waghorn et al., 2006); (Cotter et al., 2015); (Ramos et al., 2016).

This has had and will continue impact in the beef industry as we start to lack in cattle growth, milk production and overall health by illnesses and immunosuppression. Now is the time to evaluate, demonstrate, and consider use of more productive management solutions outside anthelmintics to slow down the rate of anthelmintic resistance that spreads throughout our herds. In fact, resistance is enough of a concern that in 2018 the FDA requested animal drug companies to revise, voluntarily, the labels of drugs intended to treat certain internal parasites in livestock and horses by adding information about antiparasitic resistance (Medicine, 2019). Getting producers to comprehend that maintenance of de-wormer efficacy may lead to decreased frequency of de-worming is difficult. The more times you choose to de-worm you cattle, any of those worms that survive will increase to your resistance population. Under dosing animals will also lead to the development of resistance, thus, accurate weights are a critical component of effective anthelmintic administration.. Other actions, such as rotating pastures, and using insecticides rather than macrocyclic lactones to control insect issues will increase the effectiveness of anthelmintics.

\section{Refugia}

Refugia is the population of organism not exposed to a drug or anthelmintic. In order to alleviate selection pressure for resistance and maintain drug efficacy, management strategies increasingly aim to preserve a proportion of the parasite population in 'refugia', unexposed to treatment (Hodgkinson et al., 2019). By enhancing the refugia population we can expect a better 
kill rate by diluting the resistance population. Refugia may be the best alternate form of treatment compared to prophylactic anthemintic use in beef herds. In small ruminants, the use a FAMACHA system to determine which animals would be given an anthelmintic. The use of a selection like this is called targets selective treatment (TST). This procedure looks at treating only the ones that need it, while leaving the remaining untreated. In one study, it was shown that a TST approach achieved the same health outcome as treating the whole herd, but for $24 \%$ of the drug input (Walker et al., 2015). This helps reduce the cost for producers, while also generating refugia to help maintain future anthelmintic efficacy.

\section{Strategic Anthelmintic Use}

With the increase in anthelmintic resistance on the rise, using strategic deworming tactics to help get the most out of our anthelmintic. One component to strategic deworming is the time you choose to deworm your cattle. The best time to deworm depend on the parasite you are trying to kill. Since most GIN are similar, the same action can be taken for most of them. These parasites thrive in modern temperatures and like moist conditions. These conditions normally occur during the late spring and fall times of the year. Knowing there pre patent period is around 2-3 weeks, you should administer you anthelmintic of choice 4-6 weeks after these optimum times for the parasite. The goal is to break the lifecycle of that parasite and doesn't allow large burdens to build up in your cattle. De-worm to early and the cattle has a good chance of getting re-infected during optimum conditions, de-worm to late and significant damage and performance can be impacted.

Another format to understand herd anthelmintic resistance would to be collecting composite fecal samples. Using composite fecal samples is a good method for detection of 
anthelmintic resistance as this procedure is known to be $98 \%$ in agreement with doing each individual sample (George et al., 2017). Understanding that collecting FEC can be time consuming, by collecting a proportion of random samples can help give an idea of where your parasite burden is on your farm. Common practices like these will help a producer understand parasites on a farm and the resistance you may have. This also helps show when and who should be treated with an anthelmintic to continue to have success with anthelmintic killing the parasites. Another stagey would include using two different classes of anthelmintics as a combination treatment. By combining the two classes, the resistance worms of one class will still be susceptible to the new class added, and therefore kill them. Some off the advantages of this include the producers having to purchase twice the amount of anthelmintic and if don't or managed incorrectly, you could develop parasites that are resistant to both anthelmintics and have no remaining options.

\section{Economics of Anthelmintic Resistance}

Although predicting economic losses is difficult, we can be certain due to the increase in anthelmintic resistance that parasitized cattle on average tend to have less performance leading to less gains. Many parasites can decrease an animal's overall health, but GIN parasites are the most common internal parasites affecting cattle and can detrimentally affect profitability (Walker et al., 2013). As it is important for producers to limit the impact parasites have as per cattle producers make their money off pounds and added premiums for carcass quality There has been very little research looking into carcass evaluation between cattle with high levels of parasites vs cattle with low amounts. These lower gains lead to less profitability for producers. Knowing there are higher dollars placed on the cattle killed than have high carcass quality, cattle that are higher levels of parasites tend to have lower total weight, eye muscle, and area (Entrocasso et al., 
1986). Between lower feed conversion rates and less feed consumed, calves will have lower amount of intramuscular fat, thus a lower marbling score driving their price lower than the rest.

Another study performed by Iowa State showed significance in gain for the first 24 days between low level of parasites steers (31.9 eggs/gram) vs cattle with higher levels of parasites (228.9 eggs/gram). The lower parasite steers also had tendencies of fewer days on feed, fewer health treatments, higher dressing percentage, more 12th rib fat, increased yield grade and marbling score. All things premiums are based off of to give the producers max profit for his cattle. Also, total treatment cost of high vs. low steers was $\$ 30.33$ vs $\$ 10.51$, respectively. Leading to a breakeven price of $\$ 107.37 / \mathrm{CWT}$ for low steers and \$146.28/CWT for high steers (Clark et al., 2014). These studies were conducted throughout the Midwest, southeastern U.S., and other countries makes us question how effective our anthelmintic drugs are working in the Appalachian region. 


\section{Chapter 2: Material and Methods}

\section{Central WV Feeder Calf Pool Sampling}

To evaluate the status of anthelmintic efficacy in weaned calves, we analyzed samples from nine different producers of backgrounded calves $(n=142)$ located in central WV. These samples were collected by each producer and then given an anthelmintic of their choice. Samples were kept cool by ice packs in coolers and sent immediately to West Virginia University where they were placed in the refrigerator until processed. Samples were collected from the rectum and labeled by animal number to reduce contamination from other samples. All samples were processed within 1-5 days after receiving them by modified McMaster technique. Two grams of each sample was weighted out and mixed with $28 \mathrm{~mL}$ of saturated salt solution (specific gravity of 1.20) and contents were filtered through double strained cheese cloth to remove any large particles or unwanted material. The remaining solution was pipetted into McMaster counting slides were each column was counted and the total was multiplied by 50 to calculate eggs/gram. Anthelmintics used from these producers included Dectomax ${ }^{\mathrm{TM}}$ (moxidectin) and Safeguard ${ }^{\mathrm{TM}}$ (fenbendazole). After 14 days, additional fecal samples were collected from the same cattle and analyzed using the same procedure as before. Reductions percentages were assessed from data to determine anthelmintic efficacy. Also, to be noted, another producer sent in 25 samples from the same cattle pool and all calves were at 0 eggs/gram when analyzing the samples and the anthelmintic of his choice was Long Range.

\section{Sampling of Bulls in Appalachian Region}

Samples were collected from bulls located at test locations across the Appalachian region. Locations included Wardensville Bull test located in Wardensville, WV, Southwest VA (SWVA) Bull test located in Wytheville, VA, and Culpeper Bull Test located in Culpeper, VA. 
Samples were collected upon arrival of bulls to test locations and were assessed for their quantity of strongylid-type eggs. Over a four-year period, over one thousand samples were collected and analyzed for this data.

Wardensville Bull test located in the eastern panhandle of West Virginia, enrolls bulls from WV, PA, VA, NY, and surrounding states. Due to the lack of significant numbers of other breeds within the test, samples from Angus bulls were only used for the data analysis. The anthemintic used at Wardensville was Fenbendazole otherwise known as Safe-Guard® given orally. Samples were collected from 2017 to 2020 in late October and then again in midNovember to access reduction percentages. During this span we collected samples from over 540 angus bulls.

Culpeper Bull test is located in Northern Virginia and has entries of bulls mainly from VA but also WV. Unlike Wardensville and SWVA Bull Tests, the Culpeper Bull Test is operated from June to December. Due to the time of the test, these bulls are fall-born. Samples were collected during a three-year time span from 2018-2020.The anthelmintic used at Culpeper is Moxidectin, also known as Cydectin ${ }^{\circledR}$. The mode of administration was a topical pour-on.

Lastly, is the Wytheville (SWVA) bull test and included bulls from VA, WV, NC, and TN. Collections of SWVA occurred in the beginning of October and re-sampled 21 days later at the end of October. Bulls from SWVA were broken down into two groups, Junior and Senior. The junior group were spring-calved bulls, while the senior group were fall-born bulls that would be turning into yearlings at this time. Samples were collected during a three-year time span from 2018-2020. The anthelmintic used during the SWVA bull test was also Moxidectin via the pour on solution of Cydectin®. 
To collect a sample, we used latex gloves and collected a golf-size ball size of fecal matter from the rectum of each bull. All samples where then labeled and processed individually. During transportation all the samples were placed in a cooler with ice packs to reduce the temperature and stored in a refrigerator. Fecal egg counts of all samples were conducted within 1-3 days after collection using the modified McMasters technique (Whitlock, 1948). Two grams of each fecal sample was weighed and mixed with $28 \mathrm{~mL}$ of saturated salt solution (specific gravity 1.20 ) and the contents where filtered through double layer cheesecloth to remove and large particles. The remaining solution was pipetted into a McMaster counting slide and each row was counted and multiplied by 50 to determine eggs/g of feces.

After 14-21 days, the procedure repeated itself and we observed the reductions post anthelmintic treatment to determine a reduction percentage. Reduction percentage was calculated by taking the initial sample and subtracting it by the post sample and dividing by the initial sample.

\section{Statistical Analysis}

Statistical analysis was conducted using SAS (SAS Institute Inc., Cary, NC). All data were analyzed using proc general linear model of SAS, with fixed effect on location, year and interactions. FEC data were first adjusted for normality using the natural log of FEC, multiplied by $\left.100\left(\mathrm{LN}(\mathrm{FEC})^{*} 100\right)\right)$. Data was found to be significant when $\mathrm{p}<0.05$. 


\section{Chapter 4: Results}

\section{Central WV Calf Pool Data}

Eight participating farms located in central West Virginia agreed to send us fecal samples they collected from a group of calves while backgrounding for preparation to enter feed yards or retained as replacement heifers. Together, 166 calves came from these 8 farms and samples were processed immediately after arrival. Six farms totaling in 104 calves used Moxidectin and had an average reduction percentage of $28 \%$. Farms varied from $-85 \%$ to $73 \%$ reduction. After treatment calves still had a high parasite load with the highest being of 588 eggs/gram and as low as 85 eggs/gram after treatment. Safeguard oral drench was used by 2 farms and together they totaled 39 calves. Calves from those farms had an $86 \%$ and $97 \%$ FEC reduction and had a average FECR\% of $90 \%$ after the treatment. (Table 1)

\section{Anthelmintic Resistance at Appalachian Bull Test Stations}

Data were collected from Wardensville, WV the past four years, Culpeper, VA, and Wytheville, VA the past three years (Table 2). During the four-year period, bulls from the Wardensville Test had an FECR\% of 98\% in 2017, 97\% in 2018, 93\% in 2019, and 98\% in 2020 with an average of 96.7\%. While bulls from the Culpeper Test had and FECR\% of 50\% in 2018, $29 \%$ in 2019, and $0 \%$ in 2020 with an average of 26.3\%. Lastly, bulls from the SWVA Test had FECR\% of $16 \%$ in 2018, and $19 \%$ in 2019, and $51 \%$ in 2020 with an average of $28.6 \%$ reduction.

\section{Transition Average Daily Gain at Appalachian Bull Tests Stations}

Bulls from the Wardensville test had an ADG of $1.53 \mathrm{~kg} / \mathrm{d}$ in $2017,3.26 \mathrm{~kg} / \mathrm{d}$ in 2018 , $1.77 \mathrm{~kg} / \mathrm{d}$ in 2019 , and $1.77 / \mathrm{d} \mathrm{kg}$ in 2020 with an average of $2.115 \mathrm{~kg} / \mathrm{day}$. Whereas bulls from the Culpeper Test had an ADG of $2.52 \mathrm{~kg} / \mathrm{d}$ in $2018,1.09 \mathrm{~kg} / \mathrm{d}$ in 2019 , and $2.02 \mathrm{~kg} / \mathrm{d}$ in 2020 
with an average of $1.93 \mathrm{~kg} / \mathrm{d}$. Lastly, bulls from the SWVA Test averaged $0.89 \mathrm{~kg} / \mathrm{d}$ in 2018 , $0.55 \mathrm{~kg} / \mathrm{d}$ in 2019, and $1.19 \mathrm{~kg} / \mathrm{d}$ in 2020 with an average of $0.89 \mathrm{~kg} /$ day. (Table 3)

\section{Arrival fecal egg count at Appalachian Bull Tests Stations}

Each year Wardensville saw a decrease in the amount of eggs/gram each calf entered with. In 2017 bulls averaged $246.4 \mathrm{egg} / \mathrm{g}$, while in 2018 that decreased to $126.5 \mathrm{eggs} / \mathrm{g}, 80.46$ eggs/g in 2019 and 28.93 eggs/g in 2020. Bulls from the Culpeper Test entered averaging 63.02 eggs/g in 2018, 105.26 eggs/g in 2019, and in 2020 they averaged 41.11 eggs/g. In SWVA Test, bulls in 2018 averaged 159.34 eggs/g, in 2019 they had 152.70 eggs/g and 80.33 eggs/g in 2020 (Table 3) 


\section{Chapter 5: Discussion}

Beef cattle across the US are experiencing the impact of parasitism on production as parasites are becoming resistant to anthelmintics and specifically to drugs that are formulated for pour-on application. The terrain and environment in Appalachia allow for high utilization of forage resources, thus increasing the exposure of cattle to parasites found in the environment. Lack of anthelmintic efficacy is presenting as a reduction in performance in a variety of traits that has the potential to affect profitability in cow-calf operations in this region. The effects of parasitism on beef cattle production manifests as loss of growth, which initially affects weight of weaned and backgrounded calves. However, this loss in early weight gain can have continued effects that are observed in feedlot grower and finishing phases. Therefore, when anthelmintics are used but are ineffective, the worm burden in calves entering feed yards may extend or exacerbate the transition period ultimately increasing days on feed and increasing the frequency of health treatments. When these events are taken together, they affect profitability for the feedlot operator. When feedlot operators consistently experience transition difficulty from calves of a unique region, they will limit investment into those calves resulting in lower prices of backgrounded calves coming from those regions. This information makes it imperative for producers to know the efficacy of anthelmintics they are using to avoid the deleterious impact of residual parasitic infection in weaned calves.

To model this interaction, backgrounded Angus bulls entering performance tests at three distinct bull test stations were used and evaluated over a period of three years. These data showed that bulls treated with moxidectin showed an average reduction percentage of $28.6 \%$ and 26.3\% between Wytheville and Culpeper, respectively. Whereas, bulls that entered Wardensville, treated with Fenbendazole, averaged a 96.7\% reduction over the same time span. 
These data demonstrate that resistance to moxidectin or other macro-cyclic lactone are congruent with multiple other sources. (Gasbarre, 2014), (Kaplan et al, 2012), and (Avramenko et al, 2020)

Although due to the different management strategies and not knowing each animal's pretest environment makes comparing these results amongst each test very difficult. More so we observed any treads within each test locations found some valuable information. When looking at Wardensville we saw the impact of what an effective anthelmintic can have in helping animal performance. As the bulls from Wardensville in 2017 had the highest FEC arrival of all test locations over all the years. Due to a $98 \%$ reduction they were still able to manage $1.53 \mathrm{~kg} / \mathrm{d}$. We can assume that if left untreated these bulls would have suffered lower weight gains. Since cattle treated with Fenbenazole can eliminate a parasitic infection better than cattle treated with Moxidectin and we also believe in a constant environment they would have improved weight gains over a period of time making the transition from producer to feedlot more profitable for the buyers.

These data could also indicate there might be a threshold to remain under in order to keep the performance lost to a minimum. These data from Culpeper in 2018 and 2019 also back up that logic as well. Both years were treated with Moxidectin and ADG differences were observed between the two years $(2.52 \mathrm{~kg}$ vs. $1.09 \mathrm{~kg})$, respectively. The only main difference was the level of infection in these bulls retained after administration of Moxidectin $(34.0,76.0)$ respectively. Since Culpeper in 2018 had a lower FEC than 2019, they were able to have similar performance gain to bulls at Wardensville even though reduction percentage for the two years was $50 \%$ and $29 \%$, respectively. The same can be said for Wytheville, as their greatest weight gain $(1.19 \mathrm{~kg} /$ day) comes from the year they gave the lowest FEC (39.2) after Moxidectin was given in 2020. This makes you wonder what kind of gains to expect from our calves we send out 
west if they were are unable to clear a parasitic infection. We can assume that steers leaving and heading to feedlots or other cattle that are being shipped out west to be placed on feed from these areas will exhibit similar negative affects similar to the bulls in Wytheville. Ultimately this places a poor reputation on cattle from the southeast and eastern U.S. and these cattle lack can lack potential for growth upon arrival.

With all the information given, I think in the future we can adjust these protocols to maximize animal performance. Knowing that Wardensville and Culpeper are kept in dry lots, both locations could be treated with Fenbendazole and I would expect Culpeper to have an increase reduction \%. Since Wytheville bulls are located in paddocks, they have the ability to graze some during the test duration. For these bulls I would administer both Moxidectin and Fenbenazole. I would expect with both anthelmintic classes given we could increase the reduction $\%$ greatly and even improve weight gain amongst these bulls.

Also, bulls that entered Wardensville saw a decrease in arrival FEC over the years. Data was presented to the station manager and clients and customers of the bull test and they were informed of these findings. This decrease in EPG upon arrival can be contributed to the fact that producers and farmers are incorporating our findings into their anthelmintic protocols and seeing an improved kill rate and lower worm burdens. It is important to continue to increase the amount of research of anthelmintic resistance in beef cattle, as it should be a top priority within the world. Other ways to educate others are to look at cattle FEC and culture their feces to determine which species have developed resistance to certain anthelmintic. By increasing awareness, we will be able to slow the spread of resistance and maximize cattle performance. If we choose to do nothing, we will find ourselves with the same issues as the small ruminants across the world with 
their anthelmintic resistance. With these data we can improve the cattle leaving these regions and heading to feed yards throughout the United States. 
Table 1: Fecal Egg Count Reduction in calves from the central WV Calf Pool

\begin{tabular}{|cccccc|}
\cline { 4 - 5 } Farm & N & Dewormer & $\begin{array}{c}\text { Pre- } \\
\text { Dewormer }\end{array}$ & $\begin{array}{c}\text { Post- } \\
\text { Dewormer }\end{array}$ & Reduction (\%) \\
\hline A & 11 & Moxidectin & 59 & 109 & -85 \\
B & 21 & Moxidectin & 129 & 129 & 0 \\
C & 10 & Moxidectin & 315 & 85 & 73 \\
D & 26 & Moxidectin & 1104 & 588 & 47 \\
E & 15 & Moxidectin & 327 & 453 & -39 \\
F & 20 & Moxidectin & 103 & 93 & 10 \\
G & 14 & Fenbendazole & 175 & 25 & 86 \\
H & 25 & Fenbendazole & 125 & 4 & 97 \\
\hline \hline & Project Average & $\mathbf{2 9 2}$ & $\mathbf{1 8 6}$ & $\mathbf{2 4}$ \\
\hline
\end{tabular}


Table 2: Anthelmintic resistance measured in fecal egg count reduction percentage (FECR \%)

\begin{tabular}{lccc}
\hline Location & Anthelmintic & Year & Reduction \% \\
\hline Wardensville & Fenbendazole & 2017 & 98 \\
& & 2018 & 97 \\
& & 2019 & 93 \\
Culpeper & 2020 & 98 \\
& Moxidectin & 2018 & 50 \\
& & 2019 & 29 \\
Wytheville & Moxidectin & 2020 & 0 \\
& & 2018 & 16 \\
& & 2020 & 19 \\
\hline
\end{tabular}


Table 3: Performance and FEC data from bull tests in Appalachian region

\begin{tabular}{|c|c|c|c|c|c|c|c|}
\hline Year & Anthelmintic & $\begin{array}{l}\text { No. of } \\
\text { Bulls }\end{array}$ & $\begin{array}{c}\text { Del. } \\
\text { FEC } \\
\text { (Eggs/ } \\
\text { gram) }\end{array}$ & $\begin{array}{c}\text { Post FEC } \\
(\text { Eggs/Gram })\end{array}$ & $\begin{array}{l}\text { Del. } \\
W T \\
(k g)\end{array}$ & $\begin{array}{l}\text { On- } \\
\text { Test } \\
\text { WT } \\
(\text { kg })\end{array}$ & $\begin{array}{c}\text { Trans. } \\
\text { ADG } \\
(\mathrm{kg})\end{array}$ \\
\hline Ward. '17 & Fenbendazole & 132 & 246.9 & 3.8 & 353.21 & 373.4 & 1.53 \\
\hline Ward. '18 & Fenbendazole & 145 & 126.5 & 3.31 & 310.93 & 356.8 & 3.26 \\
\hline Ward. '19 & Fenbendazole & 128 & 80.46 & 5.86 & 313.1 & 337.9 & 1.77 \\
\hline \multirow[t]{2}{*}{ Ward. '20 } & Fenbendazole & 139 & 28.93 & 0.36 & 368.78 & 420.0 & 1.77 \\
\hline & & 544 & & & & & 2.11 \\
\hline Culpeper '18 & Moxidectin & 91 & 63.02 & 34.0 & 370.63 & 406.42 & 2.52 \\
\hline Culpeper '19 & Moxidectin & 76 & 105.26 & 76.0 & 355.16 & 384.64 & 1.09 \\
\hline \multirow[t]{2}{*}{ Culpeper '20 } & Moxidectin & 91 & 41.11 & 41.2 & 366.66 & 395.06 & 2.02 \\
\hline & & 259 & & & & & 1.93 \\
\hline Wytheville '18 & Moxidectin & 91 & 133.51 & 133.51 & 354.4 & 369.4 & 0.89 \\
\hline Wytheville '19 & Moxidectin & 74 & 127.50 & 127.50 & 396.4 & 407.0 & 0.55 \\
\hline \multirow[t]{2}{*}{ Wytheville '20 } & Moxidectin & 89 & 80.33 & 39.2 & 388.6 & 413.5 & 1.19 \\
\hline & & 254 & & & & & 0.89 \\
\hline
\end{tabular}




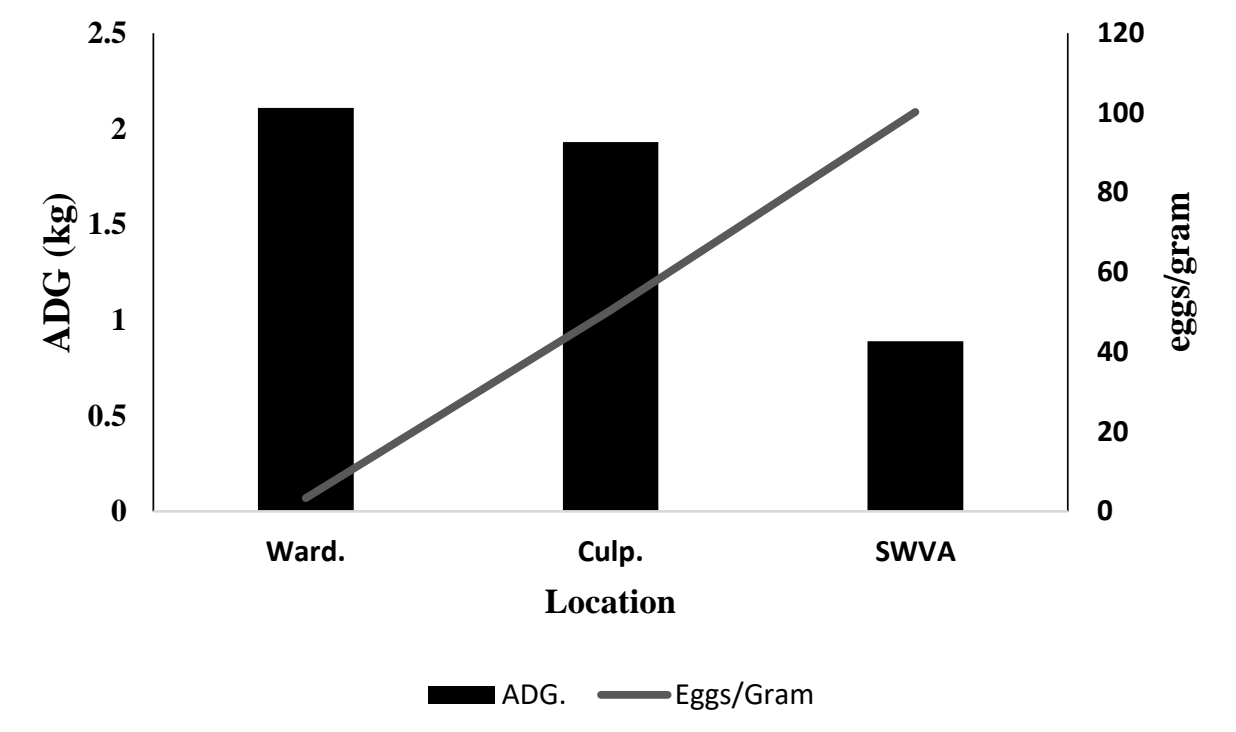

Figure 1: Growth performance measures compared to on-test FEC.

Transitional ADG is plotted against the FEC after the bulls were administered their anthelmintic. 


\section{Literature Cited}

Abongwa, M., R. J. Martin, and A. P. Robertson. 2017. A BRIEF REVIEW ON THE MODE OF ACTION OF ANTINEMATODAL DRUGS. Acta Vet (Beogr). 67:137-152. doi:10.1515/acve2017-0013.

Avramenko, R. W., E. M. Redman, C. Windeyer, and J. S. Gilleard. 2020. Assessing anthelmintic resistance risk in the post-genomic era: a proof-of-concept study assessing the potential for widespread benzimidazole-resistant gastrointestinal nematodes in North American cattle and bison. Parasitology. 147:897-906. doi:10.1017/S0031182020000426.

Beck, M. A., D. D. Colwell, C. P. Goater, and S. W. Kienzle. 2015. Where's the risk? Landscape epidemiology of gastrointestinal parasitism in Alberta beef cattle. Parasites Vectors. 8:434. doi:10.1186/s13071-015-1040-x.

Clark, C. A., P. J. Gunn, J. Dedrickson, and J. Sorenson. 2014. Effects of Internal Parasite Infection at Feedlot Arrival on Performance and Carcass Characteristics in Beef Steers. 0 ed. Iowa State University, Ames (Iowa). Available from: https://www.iastatedigitalpress.com/air/article/id/6571/

Corwin, R. M. 1997. Economics of gastrointestinal parasitism of cattle. Veterinary Parasitology. 72:451-460. doi:10.1016/S0304-4017(97)00110-6.

Cotter, J. L., A. Van Burgel, and R. B. Besier. 2015. Anthelmintic resistance in nematodes of beef cattle in south-west Western Australia. Vet Parasitol. 207:276-284.

doi:10.1016/j.vetpar.2014.11.019. 
Entrocasso, C. M., J. J. Parkins, J. Armour, K. Bairden, and P. N. McWILLIAM. 1986.

Production, parasitological and carcase evaluation studies in steers exposed to trichostrongyle infection and treated with a morantel bolus or fenbendazole in two consecutive grazing seasons. Research in Veterinary Science. 40:76-85. doi:10.1016/S0034-5288(18)30489-2.

Forbes, A. B., K. L. Cutler, and B. J. Rice. 2002. Sub-clinical parasitism in spring-born, beef suckler calves: epidemiology and impact on growth performance during the first grazing season. Veterinary Parasitology. 104:339-344. doi:10.1016/S0304-4017(01)00640-9.

Fox, M. T. 1997. Pathophysiology of infection with gastrointestinal nematodes in domestic ruminants: recent developments. Veterinary Parasitology. 72:285-308. doi:10.1016/S03044017(97)00102-7.

Gasbarre, L. C. 2014. Anthelmintic resistance in cattle nematodes in the US. Veterinary Parasitology. 204:3-11. doi:10.1016/j.vetpar.2014.03.017.

Gasbarre, L. C., L. L. Smith, E. Hoberg, and P. A. Pilitt. 2009a. Further characterization of a cattle nematode population with demonstrated resistance to current anthelmintics. Veterinary Parasitology. 166:275-280. doi:10.1016/j.vetpar.2009.08.019.

Gasbarre, L. C., L. L. Smith, J. R. Lichtenfels, and P. A. Pilitt. 2009b. The identification of cattle nematode parasites resistant to multiple classes of anthelmintics in a commercial cattle population in the US. Veterinary Parasitology. 166:281-285. doi:10.1016/j.vetpar.2009.08.018.

George, M. M., K. L. Paras, S. B. Howell, and R. M. Kaplan. 2017. Utilization of composite fecal samples for detection of anthelmintic resistance in gastrointestinal nematodes of cattle. Vet Parasitol. 240:24-29. doi:10.1016/j.vetpar.2017.04.024. 
Hodgkinson, J. E., R. M. Kaplan, F. Kenyon, E. R. Morgan, A. W. Park, S. Paterson, S. A. Babayan, N. J. Beesley, C. Britton, U. Chaudhry, S. R. Doyle, V. O. Ezenwa, A. Fenton, S. B. Howell, R. Laing, B. K. Mable, L. Matthews, J. McIntyre, C. E. Milne, T. A. Morrison, J. C. Prentice, N. D. Sargison, D. J. L. Williams, A. J. Wolstenholme, and E. Devaney. 2019. Refugia and anthelmintic resistance: Concepts and challenges. International Journal for Parasitology: Drugs and Drug Resistance. 10:51-57. doi:10.1016/j.ijpddr.2019.05.001.

Larraillet, L., A. B. Forbes, and J.-J. Pravieux. 2012. Abattoir survey of abomasal lesions associated with ostertagiosis in adult cattle. Veterinary Record. 171:299-299. doi:https://doi.org/10.1136/vr.100651.

Lawrence, J. D., and M. A. Ibarburu. 2007. "Economic Analysis of Pharmaceutical Technologies in Modern Beef Production." Proceedings of the NCCC-134 Conference on Applied Commodity Price Analysis, Forecasting, and Market Risk Management. Chicago, IL.

LongRange ${ }^{\circledR}$ (eprinomectin) | Boehringer Ingelheim Vetmedica. Available from: https://www.bi-vetmedica.com/species/cattle/products/longrange.html\#description Loyacano, A. F., J. C. Williams, J. Gurie, and A. A. DeRosa. 2002. Effect of gastrointestinal nematode and liver fluke infections on weight gain and reproductive performance of beef heifers. Veterinary Parasitology. 107:227-234. doi:10.1016/S0304-4017(02)00130-9.

MACROCYCLIC LACTONES Veterinary-Systemic. 2006. 27.

McKellar, Q. A., M. Mostofa, and P. D. Eckersall. 1990. Effect of Ostertagia ostertagi secretions and various putative secretagogues and inhibitors on aminopyrine accumulation in dispersed bovine abomasal gland cells. Res Vet Sci. 49:323-326. 
McKenna, P. B. 1991. Resistance to benzimidazole anthelmintics in cattle in New Zealand. N Z Vet J. 39:154-155. doi:10.1080/00480169.1991.35686.

Medicine, C. for V. 2019. Antiparasitic Resistance. FDA. Available from: https://www.fda.gov/animal-veterinary/safety-health/antiparasitic-resistance

Murray, M., F. W. Jennings, and J. Armour. 1970. Bovine ostertagiasis: structure, function and mode of differentiation of the bovine gastric mucosa and kinetics of the worm loss. Res Vet Sci. 11:417-427.

Myers, G. H., and R. F. Taylor. 1989. Ostertagiasis in Cattle. J VET Diagn Invest. 1:195-200. doi:10.1177/104063878900100225.

\section{NAHMS}

Ramos, F., L. P. Portella, F. de S. Rodrigues, C. Z. Reginato, L. Pötter, A. S. Cezar, L. A. Sangioni, and F. S. F. Vogel. 2016. Anthelmintic resistance in gastrointestinal nematodes of beef cattle in the state of Rio Grande do Sul, Brazil. Int J Parasitol Drugs Drug Resist. 6:93-101. doi:10.1016/j.ijpddr.2016.02.002.

Sanson, D. W., A. A. DeRosa, G. R. Oremus, and L. D. Foil. 2003. Effect of horn fly and internal parasite control on growth of beef heifers. Veterinary Parasitology. 117:291-300. doi:10.1016/j.vetpar.2003.09.005.

Smith, H. J. 1972. On the Persistence of Infective Ostertagia ostertagi, Cooperia oncophora and Nematodirus helvetianus on Pastures. Can J Comp Med. 36:333-338.

Smith, R. A., K. C. Rogers, S. Huse, M. I. Wray, R. T. Brandt, J. P. Hutcheson, W. T. Nichols, R. F. Taylor, J. R. Rains, and C. T. McCauley. 2000. Pasture deworming and (or) subsequent 
feedlot deworming with fenbendazole. I. Effects on grazing performance, feedlot performance and carcass traits of yearling steers. Bovine Practitioner. 34:104-114.

Stromberg, B. E., L. C. Gasbarre, A. Waite, D. T. Bechtol, M. S. Brown, N. A. Robinson, E. J. Olson, and H. Newcomb. 2012. Cooperia punctata: Effect on cattle productivity? Veterinary Parasitology. 183:284-291. doi:10.1016/j.vetpar.2011.07.030.

Sutherland, I. A., and D. M. Leathwick. 2011. Anthelmintic resistance in nematode parasites of cattle: a global issue? Trends in Parasitology. 27:176-181. doi:10.1016/j.pt.2010.11.008.

USDA- Animal and Plant Health Inspections Service- Veterinary Services-Center of Epidemiology \& Animal Health (USDA:APHIS:VS:CEAH). 2009. Parasite Control Practices on U.S. Cow-calf Operations, 2007-08. United States Department of Agriculture and Center of Epidemiology \& Animal Health, Fort Collins, CO.

Waghorn, T. S., D. M. Leathwick, A. P. Rhodes, R. Jackson, W. E. Pomroy, D. M. West, and J. R. Moffat. 2006. Prevalence of anthelmintic resistance on 62 beef cattle farms in the North Island of New Zealand. N Z Vet J. 54:278-282. doi:10.1080/00480169.2006.36711.

Walker, J. G., M. Ofithile, F. M. Tavolaro, J. A. van Wyk, K. Evans, and E. R. Morgan. 2015. Mixed methods evaluation of targeted selective anthelmintic treatment by resource-poor smallholder goat farmers in Botswana. Veterinary Parasitology. 214:80-88. doi:10.1016/j.vetpar.2015.10.006.

Walker, R. S., J. E. Miller, C. J. Monlezun, D. LaMay, C. Navarre, and D. Ensley. 2013. Gastrointestinal nematode infection and performance of weaned stocker calves in response to anthelmintic control strategies. Veterinary Parasitology. 197:152-159. doi:10.1016/j.vetpar.2013.07.011. 
Waller, P. J. 1997. Anthelmintic resistance. Veterinary Parasitology. 72:391-412. doi:10.1016/S0304-4017(97)00107-6.

Wyk, V., and J. A. (Jan Aucamp). 2001. Refugia - overlooked as perhaps the most potent factor concerning the development of anthelmintic resistance. Available from:

https://repository.up.ac.za/handle/2263/18482 